\title{
Description of corrections on electrode polarization impedance using isopotential interface factor
}

\author{
J. A. Gómez-Sánchez ${ }^{1}$ and C. J. Felice ${ }^{1,2}$ \\ 1. Laboratorio de Medios e Interfases DBI-FACET / INSIBIO-CONICET, CC 327, Tucumán 4000, Argentina \\ 2.E-mail any correspondence to: cfelice@herrera.unt.edu.ar
}

\begin{abstract}
In this paper, we propose an equation and define the Isopotential Interface Factor (IIF) to quantify the contribution of electrode polarization impedance in two tetrapolar electrode shapes. The first tetrapolar electrode geometry shape was adjacent and the second axial concentric, both probes were made of stainless steel (AISI 304). The experiments were carried out with an impedance analyzer (Solartron 1260) using a frequency range between $0.1 \mathrm{~Hz}$ and $8 \mathrm{MHz}$. Based on a theoretical simplification, the experimental results show a lower value of the IIF in the axial concentric tetrapolar electrode system which caused a lower correction of interface value. The higher value of the IIF in the adjacent electrode system was $\mathrm{K}_{\mathrm{EEI}}(1 \mathrm{~Hz}, 0.28 \mathrm{mS} / \mathrm{cm})=1.41$ and decreased when the frequency and conductance were increased, whereas in the axial concentric electrode system was $\mathrm{K}_{\mathrm{EEI}}(1 \mathrm{~Hz}$, $0.28 \mathrm{mS} / \mathrm{cm})=0.08$. The average isopotential interface factor throughout the whole range of conductivities and frequencies was 0.23 in the adjacent electrode system and 0.02 in the axial concentric electrode system. The index of inherent electrical anisotropy (IEA) was used to present an analysis of electrical anisotropy of biceps brachii muscle in vitro using the corrections of both tetrapolar electrode systems. A higher IEA was present in lower frequency where the variation below $1 \mathrm{kHz}$ was $15 \%$ in adjacent electrode configuration and $26 \%$ in the axial concentric probe with respect to full range. The IIF is then shown that it can be used to describe the quality of an electrode system.
\end{abstract}

Keywords: Concentric axial electrode, adjacent electrode, electrical anisotropy, electrode polarization impedance, index IEA

\section{Introduction}

The electrodes used in dielectric and impedance spectroscopy can have several different shapes, materials, roughness, and polarities. At low frequencies, the metallic and semiconductor electrodes produce a polarization effect between the interface of electrode and sample. When a metallic electrode and an electrolytic medium are placed in contact, an electrochemical double layer is generated on the electrode surface due to the distribution of dissimilar ions between the solid and liquid phase [1]. This charge distribution produces an electric field and modifies the ionic atmosphere. During this process some ions of solution are attracted and adsorbed toward the surface [2]. The electrode polarization depends of the ionic conductivity, physicochemical state of the electrode surface, temperature, and the sample characteristics [3]. The equivalent electrical impedance is considered as a sum of electrode polarization impedance $\left(Z_{\mathrm{EEI}}\right)$ and impedance of the solution or sample $\left(\mathrm{Z}_{\mathrm{sol}}\right)$. At lower frequencies, the contribution of an electrolytic sample has a lower impedance compared to the interface impedance. The interface impedance introduces an appreciable value compared to the sample's impedance and generally is considered as an error [4].

The contribution of electrode polarization impedance is reduced using a tetrapolar electrode configuration. Lippman pioneered this configuration [5] and it has actually since become the most common employed technique to diminish the electrode polarization impedance. This reduction in electrode polarization impedance is only causing a simplification if the measurement electrodes have the same material with equal contact area [6,7]. The tetrapolar technique is often employed in dielectric and impedance spectroscopy to measure the electrical properties of biological tissues [8-10] and some chemical compounds [11]. Several error sources in these measurements result form the physical and chemical properties of the sample [12], geometry uncertainty [13], and possible inductive effects of sample and measurement device [14]. The interface impedance is usually significant for input frequencies below $1 \mathrm{kHz}$, beyond this frequency the electrode polarization impedance becomes negligible [4].

Tetrapolar electrode systems have been widely used for measuring the impedance of tissues because they tend to remove the effect of electrode impedance, although a complex sensitivity distribution introduces a large error due to the sample volume conductor [14]. In this paper, two tetrapolar shapes were used, the first tetrapolar electrode geometry uses an adjacent configuration and the second utilizes an axial concentric. The adjacent tetrapolar electrode shape was proposed and studied by the Department of Medical Physics and Clinical Engineering at the University of Sheffield, and was used to identify premalignant changes in squamous epithelial tissue of the cervix [15] and perform virtual biopsies of squamous and columnar tissue in the esophagus [16]. The axial concentric electrode system has been used to determine the condition of a sample of food [17] and to measure physiological parameters [18].

In skeletal muscles, the anisotropy produces dissimilar values in orthogonal directions of electrical impedance spectroscopy measurements due to the intrinsic structure; the electrical conductivity along the longitudinal direction of the muscle fibers is higher compared to the transverse 
direction [19]. The hierarchical structure of the muscles consists of myofibrils grouped in any of four patterns of organization called fascicles and surround by a connective network called perimysium. Several fascicules constitute a muscle and are covered by epimysium. The intramuscular connective tissue is made up of a combination of perimysium and endomysium. The perimysium plays an important role in determining the diameter variability of connective tissue, often associated with exercise [20].

When an electric sinusoidal field is applied to muscle, the sarcotubular system presents several reorientation times of constitutive dipoles. This behavior is dependent on the frequency and intensity of the electric field applied. As the frequency of the electric field is increased, the tissue resistivity diminishes from an initial value held at low frequencies to another constant level at high frequencies [19].

The electrical anisotropy of biological tissues depends on intra- and extracellular spaces, whose heterogeneity can be characterized by the random spatial dependence of matter shaping [21]. In the membrane, the electrical properties depend on the polar lipid group orientation and the intrinsic free rotation. The influence of electric fields on membranes is related to membrane thickness and cellular radius [22].

Generally in dielectric and impedance spectroscopy measurements, the behavior of electrical anisotropy of biological tissues, especially in muscles, depends on the applied current, geometry shape, and inter-electrode separation [23-25].

Many studies using tetrapolar electrode configurations do not discuss the presence of electrode polarization impedance. Some authors even assume that tetrapolar electrode systems do not have errors due to electrode polarization [19]. In order to test the electrode polarization theories, a series of experiments were carried out to investigate the behavior of two tetrapolar electrode systems, and we define a new factor called the isopotential interface factor (IIF) to quantify the contribution of electrode polarization impedance. Based on this quantification, we propose that the IIF can be used as an indicator of quality in electrode systems.

\section{Materials and methods}

\section{Probe configurations}

The experiments were developed with two tetrapolar electrode systems built from stainless steel (AISI 304), one with adjacent shape and other with axial concentric form. The geometric design of the adjacent probe consist of four circular electrodes of $12.7 \mathrm{~mm}$ in diameter, where each electrode was placed at a vertex of a square with $25 \mathrm{~mm}$ sides, making the separation between the electrodes 18.44 $\mathrm{mm}$ (Figure 1a). The axial concentric tetrapolar electrode system has four stainless steel rings with radius of 7.94, $14.26,22.23$ and $31.75 \mathrm{~mm}$ and thickness of $1.4 \mathrm{~mm}$ (Figure 1b). For both tetrapolar probe configurations the free space was filled with liquid acrylic and given six hours to dry. Both electrode systems had been polished with sandpaper (600 ANSI). The final grain size of electrode surface was approximately $14.5 \mu \mathrm{m}$.

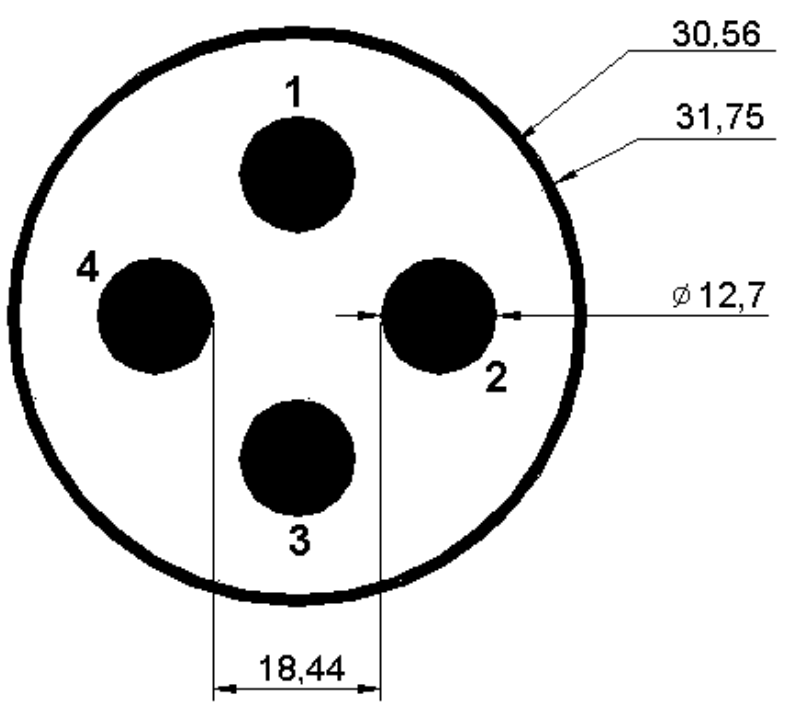

(a)

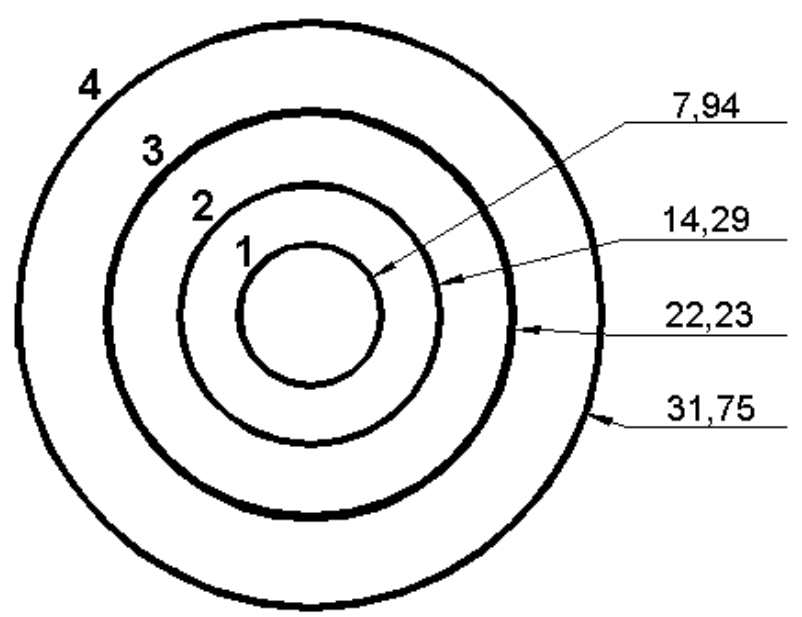

(b)

Figure 1: Electrode shapes. (a) Adjacent tetrapolar. (b) Axial concentric tetrapolar. The arrows show the dimension in millimeters.

\section{Electric Impedance Spectroscopy measurements}

The electrodes were connected to an electrochemical impedance analyzer (Solartron 1260). The current injection electrodes were between outer (1) and inner (4) ring. The voltage were sensing in both intermediate electrodes ( 2 and 3). The following sequence of Solartron terminal connection was used in both electrodes: electrode 1 was given Gen output; electrode 2 was given Voltage 1-HI; electrode 3 was given Voltage 1-LO; and electrode 4 was given Current. In all experiments, $50 \Omega$ coaxial cables, 1 meter in length with BNC connectors were used. The Solartron was connected by USB port to an IBM compatible computer using a GPIB card from National Instruments. We applied a sinusoidal constant current of 0.5 
$\mathrm{mA}$ in a frequency range between $0.1 \mathrm{~Hz}$ and $8 \mathrm{MHz}$. During the measurements, the values were displayed using ZView and the post-processing analysis was done through MATLAB $^{\circledR}$.

\section{Muscle impedance measurements}

We selected a muscle of Brahman-Zebu crossed cattle from a commercial meat processing plant, that was able to cover the total electrode area. The muscle impedance measurements were carried out four hours after slaughter in the Laboratory of Materiales Nanoestructurados $y$ Funcionales de la Universidad Nacional de Colombia (Sede Manizales). The room in which the experiments were conducted was kept a temperature of $20{ }^{\circ} \mathrm{C}$ with a relative humidity of $65 \%$. The electrodes were supported by tweezers attached to a vertical bar to avoid errors in electrical measurements due to unpredictable movements and dissimilar pressures over the muscle sample. Measurements of electrical impedance with both tetrapolar electrode systems were carried out along the transverse and longitudinal myofibril directions of the samples and repeated three times. A schematic of the impedance measurement experiments in muscles is show in Figure 2.
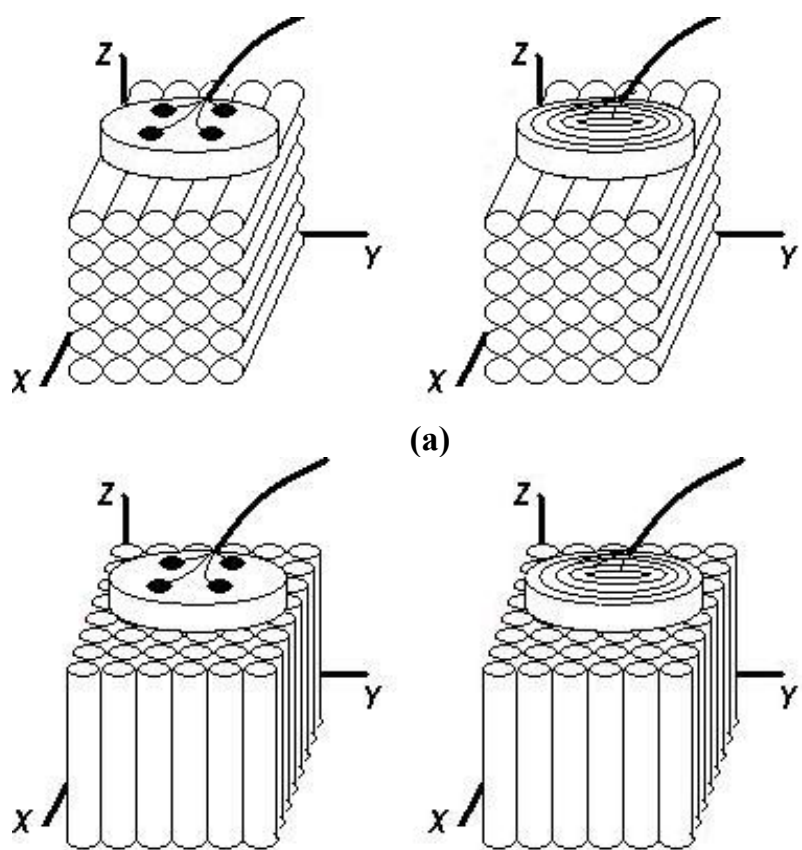

(a)

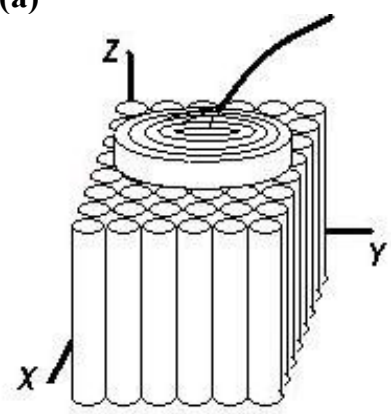

(b)

Figure 2: Schematic measurements in muscle (a) Measurements along longitudinal direction of fiber axis with both electrode configurations (b) Measurements in transverse direction with both electrode configurations.

An index of muscular bidirectional electrical anisotropy (inherent electrical anisotropy, or IEA) proposed in an earlier paper [26] and described in equations $1 \mathrm{a}$ and $1 \mathrm{~b}$, was used.

$$
\begin{aligned}
I A E & =\sqrt{\left|Z_{L}\right|^{2}+\left|Z_{T}\right|^{2}-2\left|Z_{L}\right|\left|Z_{T}\right| \cos (90-\alpha)} \\
\alpha & =a b s\left(\theta_{T}+\theta_{L}\right)
\end{aligned}
$$

In equations $1 \mathrm{a}$ and $1 \mathrm{~b}$ :

$Z_{L}$ : Electrical impedance along the myofibril axis direction

$Z_{T}$ : Electrical impedance along the transverse myofibril axis direction

$\theta_{L}$ : Phase angle of electrical impedance along the longitudinal direction $\left(Z_{L}\right)$

$\theta_{T}$ : Phase angle of electrical impedance along the transverse direction $\left(Z_{T}\right)$

\section{Isopotential interface factor}

The complex impedance measure $\left(Z_{m e d}\right)$ is considered as the sum of both complex impedances: solution $\left(Z_{S o l}\right)$ and electrode polarization impedance $\left(Z_{E E I}\right)$.

$$
Z^{*}{ }_{\text {med }}=Z^{*}{ }_{\text {sol }}+Z^{*}{ }_{E E I}
$$

Complex impedance is defined by both real and imaginary components. If only the real part (resistance) is considered, equation 2 can be rewritten as:

$$
R_{\text {med }}=R_{\text {sol }}+R_{E E I}
$$

Using the resistance definition, the resistance value depends of sample conductivity and the geometry ratio between the length $(L)$ and cross-sectional area $(A)$ of the sample as seen in equation 4 .

$$
R=\frac{1}{\sigma} \frac{L}{A}
$$

Combining the results of equations 3 and 4 and additionally considering the conductivity of interface as a contributing factor (isopotential interface factor, $\mathrm{K}_{E E I}$ ), equation 5 can be arrived at:

$$
R_{\text {med }}=R_{\text {sol }}+R_{E E I}=\frac{1}{\sigma_{\text {Sol }}} \frac{L}{A}+\mathrm{K}_{E E I} \frac{L}{A}
$$

$\mathrm{K}_{E E I}$ can then be expressed by:

$$
\mathrm{K}_{E E I}=\frac{R_{m e d}-R_{S o l}}{\left(\frac{L}{A}\right)}
$$

The measurements of conductivity in $\mathrm{NaCl}$ solutions can be considered constant for frequencies above $1 \mathrm{kHz}$. The variability of impedance observed at frequencies below 1 $\mathrm{kHz}$ is due to the electrode polarization impedance contribution. Now we call the conductivity solution $\sigma_{\text {Sol }}$ and substitute it into equation 4 to obtain

$$
R_{\text {sol }}=\frac{1}{\sigma_{\text {Sol }}} \frac{L}{A} \cong R_{1 k H z}
$$


The isopotential interface factor $\left(\mathrm{K}_{E E I}\right)$ can then be shown to vary with applied frequency and sample conductivity:

$$
\mathrm{K}_{I E E}\left(f, \sigma_{S o l}\right)=\frac{R_{m e d}(f)-R_{1 k H z}}{R_{1 k H z} * \sigma_{S o l}}
$$

where $R_{\text {med }}(f)$ is the resistance at one frequency and $R_{1 \mathrm{kHz}}$ is the resistance of the solution above $1 \mathrm{kHz}$.

Based on equation 8 , this factor is called isopotential when it has the same value at several frequencies and conductivities similar to contours. The isopotential interface factor depends of frequency and conductivity and shows different electrode polarization impedance behavior for each electrode shape. The factor intrinsically depends on the chemical reactions between the sample composite and physical structure of the electrode.

The isopotential interface factor was found by using $\mathrm{NaCl}$ solutions prepared with bi-distilled water of $5 \mu \mathrm{S} / \mathrm{cm}$, the concentrations had the following conductivities: 0.28 , $0.60,2.00,3.66,6.83$, and $10.0 \mathrm{mS} / \mathrm{cm}$.

We used a nonlinear equation to relate the measurements of resistance at $1 \mathrm{kHz}$ and conductivity of both electrode shapes. The coefficients were fit using the least squares method. This equation was used to correct the resistance values of measurements for both tetrapolar electrode systems along the transverse and longitudinal myofibril directions:

$$
\sigma_{m}{ }^{\prime}=e^{A[\ln R]^{2}+B[\ln R]+C}
$$

Here $A, B$, and $C$ are constants.

\section{Results}

Using a $\mathrm{NaCl}$ solution with several concentrations, we calculated the isopotential interface factor of both electrode shapes using equation 8 . Figure 3 a shows the isopotential interface factor for frequencies below $1 \mathrm{kHz}$. In this graph, the higher value of isopotential interface factor in adjacent electrode shape is $\mathrm{K}_{E E I}(1 \mathrm{~Hz}, 0.28 \mathrm{mS} / \mathrm{cm})=1.41$ and decreases when the frequency and conductance were increased. In the figure $3 \mathrm{~b}$, the isopotential interface factor of axial concentric electrode shape was $\mathrm{K}_{\mathrm{EEI}}(1 \mathrm{~Hz}, 0.28$ $\mathrm{mS} / \mathrm{cm})=0.08$. The average of isopotential interface factor through the entire range of conductivities and frequencies was 0.23 in adjacent electrode shape and 0.02 in axial concentric electrode shape.

Equation 9 was used to find the relationships between conductivity and resistance values measured at $1 \mathrm{kHz}$ by each electrode shape. The relation for the adjacent electrode system was fit to equation 10 and the axial concentric electrode system was described by equation 11 .

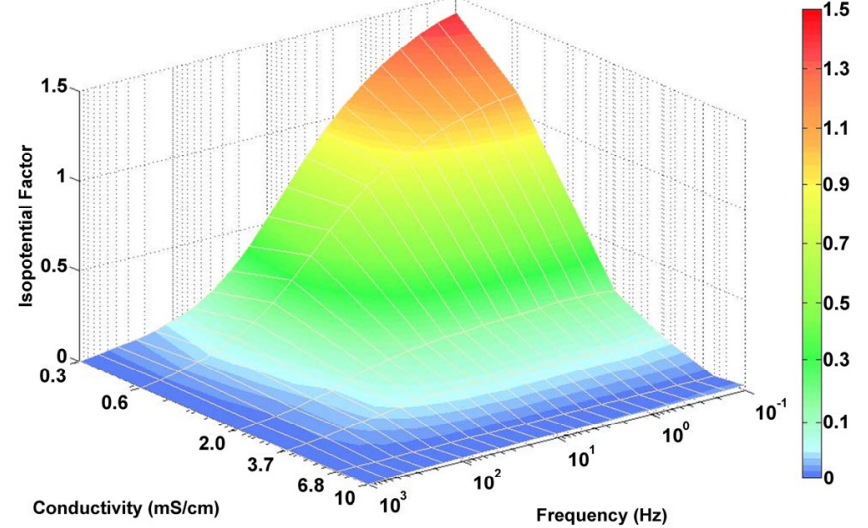

(a)

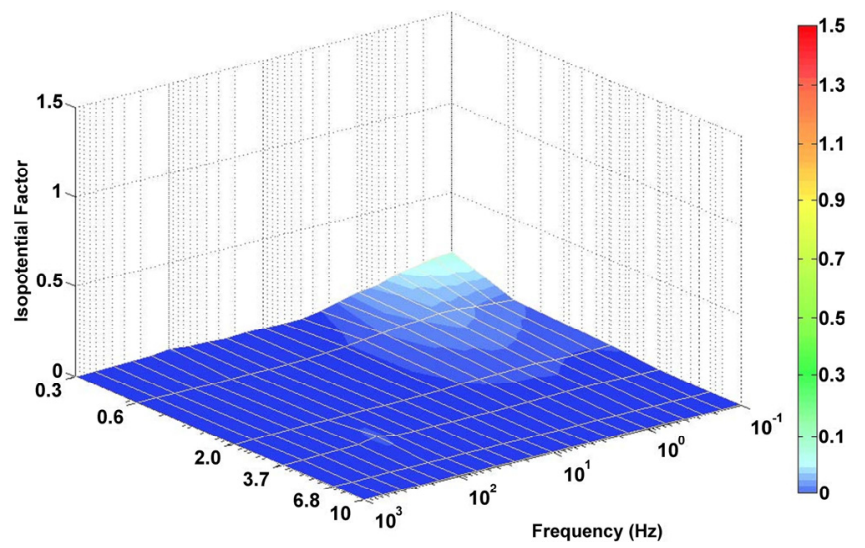

(b)

Figure 3: Isopotential interface factor for (a) adjacent electrode system and (b) axial concentric electrode system. A color bar indicates the magnitude of the isopotential interface factor in both 3D graphs. The isopotential factor was higher in adjacent shape compared with axial concentric tetrapolar electrode system.

The Pearson correlation index was 0.99 by both equations.

$$
\begin{aligned}
& \sigma_{\text {med }}{ }^{\prime}=e^{-1.2181[\ln R]^{2}-2.5098[\ln R]-4.7067} \\
& \sigma_{\text {med }}{ }^{\prime}=e^{-1.5098[\ln R]^{2}-2.1345[\ln R]-5.2642}
\end{aligned}
$$

Using equations 10 and 11, we found the conductivity of muscle with interface contribution for the whole frequency range, after the transverse and longitudinal conductivity values were adjusted to the real values using each respective isopotential interface factor. In frequencies below $1 \mathrm{kHz}$, the contribution of the interface impedance of the adjacent electrode system was higher and nonadjusted curves had more variation (Figure 4a) compared with the concentric electrode system (Figure $4 b$ ). 


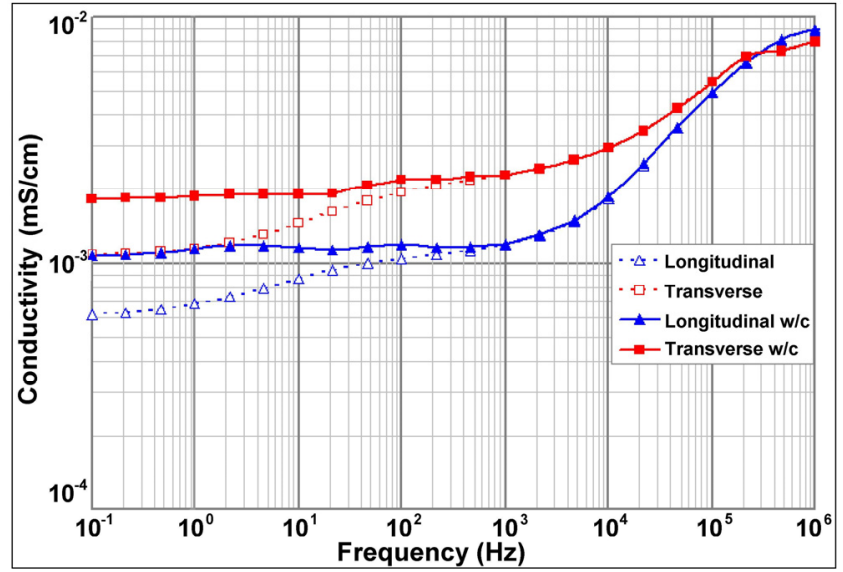

(a)

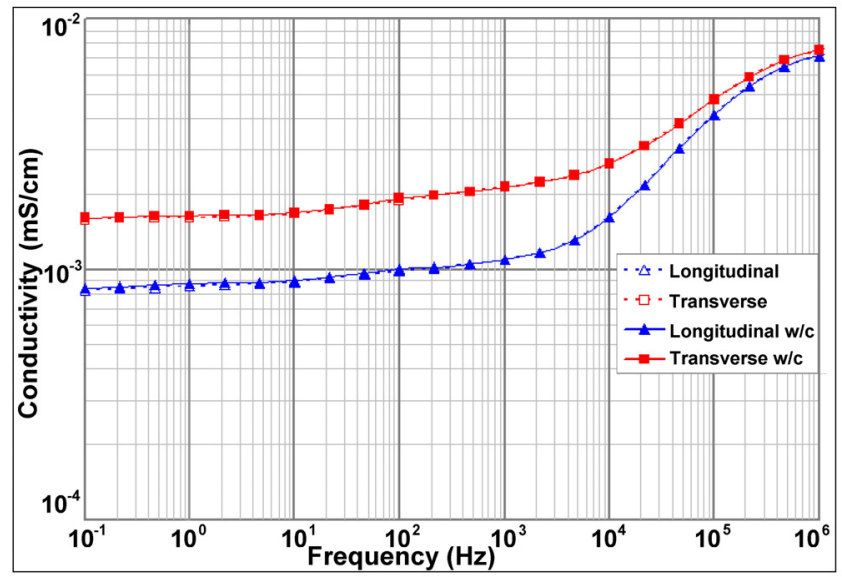

(b)

Figure 4: Muscle conductivity calculated with both respective equations. (a) Adjacent electrode, (b) concentric electrode, filled symbols are conductivity with correction by isopotential interface factor $(\Delta$ : non adjusted longitudinal conductivity, $\square$ : non adjusted transverse conductivity, $\boldsymbol{\Delta}$ : longitudinal conductivity with correction, $\mathbf{m : ~ t r a n s v e r s e ~ c o n d u c t i v i t y ~ w i t h ~ c o r r e c t i o n ) . ~}$

In the muscle sample studied, the index IEA (equation 1a) varied with frequency and electrode geometry, and the values are plotted in Figure 5. We found IEA values between 14 and 109 using the adjacent electrode system and between 9 and 82 in the axial concentric electrode system. The IEA index of biceps brachii muscle shows a higher value in the adjacent electrode shape than in the axial concentric electrode shape. Additionally, in the adjacent electrode system the full range of the index was $31 \%$ greater than for the axial concentric electrode system. The higher anisotropy was present at lower frequencies with the variation below $1 \mathrm{kHz}$ being $15 \%$ for the adjacent electrode shape and $26 \%$ in the axial concentric system with respect to full range. In frequencies below $1 \mathrm{kHz}$, the value of the IEA index presents a decrease and depends on the applied frequency. A greater diminution of the IEA index is seen in the adjacent electrode system $(85 \%)$ compared with the axial concentric electrode system (74\%). However, after $2 \mathrm{MHz}$ the IEA index increases $58 \%$ in the adjacent and $48 \%$ in then axial concentric electrode system. Using the conductive equation, we correct the IEA index to the adjacent electrode system.

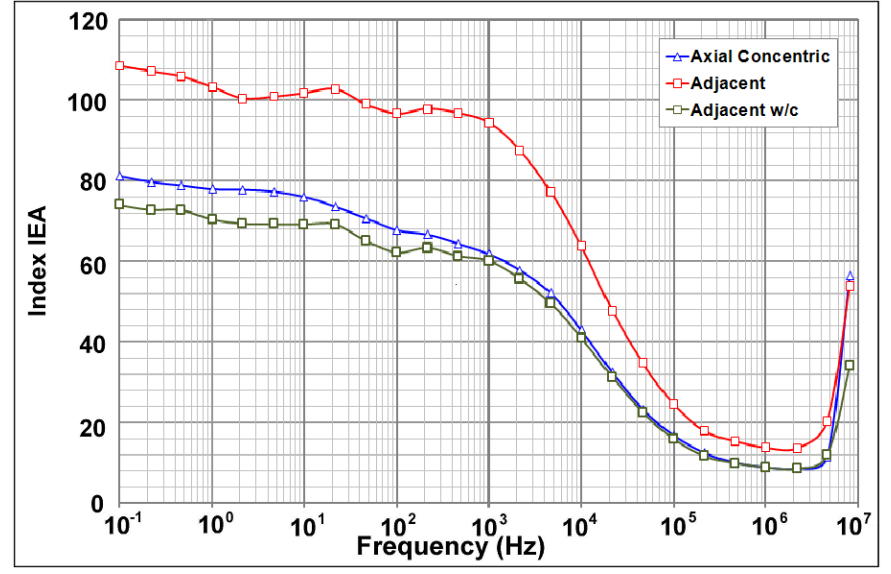

Figure 5: Values of IEA index between $0.1 \mathrm{~Hz}$ and $8 \mathrm{MHz} . \quad(\Delta$ : anisotropy values obtained with axial concentric electrode shape, $\square$ : anisotropy values obtained with adjacent electrode shape).

Based on equation $1 \mathrm{~b}$, the IEA angle was calculated and was seen to behave nonlinearly in both electrode shapes with four inflection points (Figure 6). For the adjacent electrode system the lowest value of IEA angle was $5.57^{\circ}$ at $0.1 \mathrm{~Hz}$, increased with frequency until $20.8^{\circ}$ at $10 \mathrm{~Hz}$, decreased between $10 \mathrm{~Hz}$ and $215 \mathrm{~Hz}$, and increased again to reach a peak value of $74.22^{\circ}$ at $100 \mathrm{kHz}$. The lowest value of the IEA angle in the axial concentric electrode system was $0.06^{\circ}$ at $0.2 \mathrm{~Hz}$ and the peak value was $62.5^{\circ}$ at $65 \mathrm{kHz}$. For both electrode systems, frequencies above 2 $\mathrm{MHz}$ present a new increasing range.

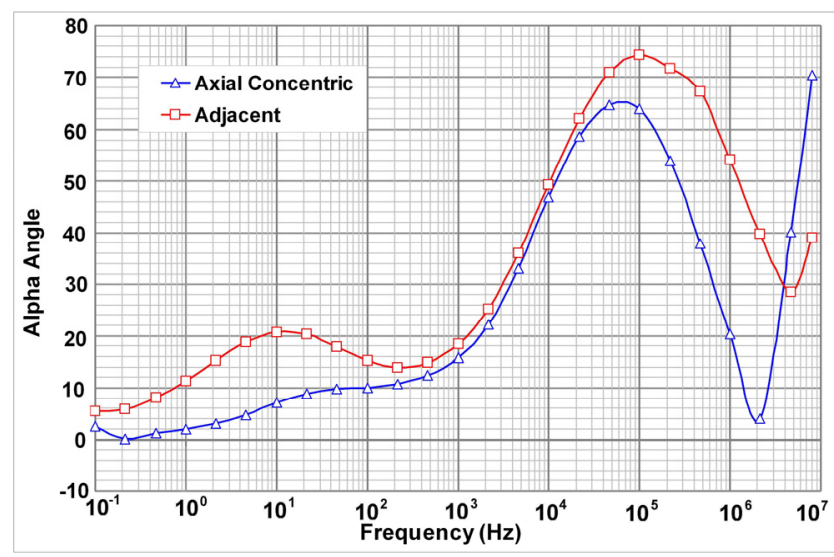

Figure 6: IEA angle. ( $\Delta$ : values obtained with axial concentric electrode shape, $\square$ : values obtained with adjacent electrode shape).

\section{Discussion}

Interface is a general term used to denote the location where two surface composites are in contact. There exists a discontinuity in chemical composition, thermodynamic, physical and electrical properties [27]. In measurements with electrodes, the electrode polarization impedance is generally eliminated or minimized due to use of several materials and geometry shapes. The literature mentions the advantage of tetrapolar configuration for the reduction of contribution of electrode electrolyte impedance at lower frequencies [28]. However, our experiments show an 
interface phenomenon in both tetrapolar geometries; in frequencies below $1 \mathrm{kHz}$, the interface impedance was higher in the adjacent electrode configuration (Figure 2a) than in the axial concentric electrode configuration. Theoretically, the behavior of tetrapolar electrode systems is expected to be unaffected by impedance gradients due to electrode polarization impedance. The current density of interface is non-uniform and this non-uniformity depends on electrode geometry [29].

In measurements of homogenous $\mathrm{NaCl}$ solution, the resistivity solution must be considered constant in frequencies below $1 \mathrm{MHz}$ [31]. At low frequencies, whenever a contribution of electrode polarization interface appears it is associated with electrode geometry, surface roughness, and the diffusion Plank equation [2]. A possible explanation of this behavior is described by fractal geometry and models based on nonlinear equations [30]. The interface phenomenon is not only associated with microscopic surface topography and the physical nature of electrodes, it also depends on the chemical composition and interactions between both the sample and electrode [32]. Feldman et al. [33] explain the electrical polarization on electrode surface as caused by an external electric field. This is also related to the oscillation or reorientation of ionic charges due to electrostatic forces inside the electrode and bulk, and this process involves the reorganization of atomic structures of sample on electrode surface [34].

Several techniques to reduce the contribution of electrode polarization interface are being developed [35]. Four-electrode or tetrapolar probes have been a preferred configuration due to their ability to compensate for electrode polarization impedance [36], but this method does not eliminate totally the interface contribution, particularly in low frequencies.

In measurements of IEA index [26], the polarization impedance can produce errors in electrical measurements. Furthermore, anisotropy values at low frequencies are influenced by the contribution of this interface polarization. An adjacent electrode configuration shows a higher value compared with axial concentric electrode, but using the IIF corrections in the IEA index calculation for adjacent electrodes similar values of IEA index in both electrode systems were obtained. In frequencies above $2 \mathrm{MHz}$, the IEA index shows a considerable increase due to the errors typically associated with high frequency for ordinary electronic designs [14].

In Figure 6 appear two regions of frequency dependency in the IAE angle: the first region was considered in frequency range between $0.1 \mathrm{~Hz}$ and $215 \mathrm{~Hz}$ and the second between $215 \mathrm{~Hz}$ and $2 \mathrm{MHz}$. In the adjacent electrode system the index and angle IEA was higher compared with the axial concentric electrode system, this behavior is more evident in low frequencies.

\section{Conclusion}

Isopotential interface factor is a useful valid simplification to describe the interface effects in electrodes, and allows accomplishing a quantitative description of the behavior of the polarization impedance. This description of electrode polarization impedance can be used as an indicator of quality in electrodes. With experimental results presented, the electric anisotropy can be measured using any of two electrode shapes though dissimilar values will be obtained. At low frequencies the isopotential interface factor must be used to calculate the contribution of electrode interface impedance and correct the IEA index. Due to these myriad factors, we believe the axial concentric tetrapolar electrode system is a good choice to measure electric properties of biological tissues.

\section{Acknowledgments}

This work has been supported by grants of PROYECTO PROCISUR TIPIFICACION, and Institutional funds from INSIBIO (Instituto Superior de Investigaciones Biológicas, CONICET). The authors thank to Dr. Oscar Hernán Giraldo Osorio, Director of Laboratorio de Materiales Nano-Estructurados y Funcionales at Universidad Nacional de Colombia, Sede Manizales and Professor William Aristizabal Botero Director of Laboratorio de Instrumentación Biofísica at Universidad de Caldas for their unconditional support in the realization of the experiments. We appreciate the valuable comments and suggestions of the reviewers.

\section{References}

1. Davey CL, Davey HM, Kell DB. On the Dielectric Properties of Cell Suspensions at High Volume Fractions.

Bioelectrochemistry and Bioenergetics. 1992;28:319-340. http://dx.doi.org/10.1016/0302-4598(92)80023-A

2. Coster HGL, Chilcott TC, Coster ACF. Impedance spectroscopy of interfaces, membranes and ultrastructures. Bioelectrochemistry and Bioenergetics. 1996;40:79-98. http://dx.doi.org/10.1016/0302-4598(96)05064-7

3. Bordi F, Cametti C, Colby RH. Dielectric spectroscopy and conductivity of polyelectrolyte solutions. J. Phys: Condens. Matter. 2004;16:R1423-R1463.

http://dx.doi.org/10.1088/0953-8984/16/49/R01

4. Felice CJ, Monitor Digital de Microorganismos: Aspectos Teóricos y Tecnológicos [PhD Dissertation]. Universidad Nacional de Tucumán, San Miguel de Tucumán. 1999.

5. Geddes LA. Who Introduced the Tetrapolar Method for Measuring Resistance and Impedance? IEEE Engineering in Medicine and Biology Magazine. 1996;15:133-134. http://dx.doi.org/10.1109/51.537070

6. Prodan C, Mayo F, Claycomb JR, Miller JH, Benedik MJ. Low-frequency, low-field dielectric spectroscopy of living cell suspensions. J. Appl. Phys. 2004;95:3754-3756. http://dx.doi.org/10.1063/1.1649455

7. Schwan HP, Ferris CD. Four-Electrode Null Tecniques for impedance Measurement with High Resolution. The Review of Scientific Instruments. 1968;39:481-485. http://dx.doi.org/10.1063/1.1683413 
8. Brown BH, Smallwood RH, Barber DC, Lawfoed PV, Rose DR. Medical Physics and Biomedical Engineering. IOP Plublishing, London, 1999 http://dx.doi.org/10.1887/0750303689

9. Cornish BH, Jacobs A, Thomas BJ, Ward LC. Optimizing electrode sites for segmental bioimpedance measurements. Physiol. Meas. 1999;20:241-250. http://dx.doi.org/10.1088/0967-3334/20/3/302

10. Scharfetter H, Structural Modeling for Impedance-Based Non-Invasive Diagnostic Methods [PhD Dissertation]. Faculty of Electrical Engineering, Technical University Graz, Graz, 1999

11. Kim SG, Sung PY, Han J, Suk WN, Tae HL, Oh IH, Hong, SA. A study on the chemical stability and electrode performance of modified $\mathrm{NiO}$ cathodes for molten carbonate fuel cells. Electrochimica Acta. 2004;49:3081-3089 http://dx.doi.org/10.1016/j.electacta.2004.01.027

12. Kybert J, Hansgent H, Pliquetti F. Dielectric properties of biological tissue at low temperatures demonstrated on fatty tissue. Phys. Med. Biol.1992;37:1675-1688 http://dx.doi.org/10.1088/0031-9155/37/8/004

13. Baysal U, Eyüboglu BM. Tissue resistivity estimation in the presence of positional and geometrical uncertainties. Phys. Med. Biol. 2000;45:2373-2388 http://dx.doi.org/10.1088/0031-9155/45/8/322

14. Grimnes S, Martinsen OG. Sources of error in tetrapolar impedance measurements on biomaterials and other ionic conductors. J. Phys. D: Appl. Phys. 2007;40:9-14 http://dx.doi.org/10.1088/0022-3727/40/1/S02

15. Brown BH, Tidy JA, Boston K, Blackett AD, Smallwood RH, Sharp F. Relation between tissue structure and imposed electrical current flow in cervical neoplasia. The Lancet. 2000;355:892-895 http://dx.doi.org/10.1016/S0140-6736(99)09095-9

16. González-Correa CA, Brown BH, Smallwood RH, Kalia N, Stoddard CJ, Stephenson TJ, Haggie SJ, Slater DN, Bradman KD. Virtual biopsies in Barret's esophagous using impedance probe. Ann. NY Acad. Sci. 1999;873: 313-321 http://dx.doi.org/10.1111/j.1749-6632.1999.tb09479.x

17. Less A, Shenstone Richards JC, Jason AC. Methods and apparatus for determining the condition of food. US Patent No. 3665302, 1972

18. Kislov AV, Novikov IA, Petrovych SV, Khomyakov ON. Biological signal sensor and device for recording biological signals incorporating the said sensor. US Patent No. 6.996.428, 2006

19. Foster KR, Schwan HP. Dielectric Properties of Tissues and Biological Materials, A Critical Review. Critical Reviews in Biomedical Engineering. 1989;17:25-104

20. Jontes JD. Theories of muscle contraction, Journal of Structure Biology. 1985;115:119-143 http://dx.doi.org/10.1006/jsbi.1995.1037

21. Brosseau C. Modelling and simulation of dielectric heterostructures: a physical survey from an historical perspective. J. Phys. D: Appl. Phys. 2006;39:1277-1294 http://dx.doi.org/10.1088/0022-3727/39/7/S02

22. Simeonova M, Gimsa J. Dielectric anisotropy, volume potential anomalies and the persistent Maxwellian equivalent body, J. Phys.: Condens. Matter. 2005; 17:7817-7831 http://dx.doi.org/10.1088/0953-8984/17/50/004
23. Gómez-Sánchez JA, Felice CJ. Determination of bidirectional electric anisotropy of muscles ex vivo using three electrode configurations. IFMBE Proceedings WC 2009 World Congress on Medical Physics and Biomedical Engineering 25, 2009

24. Steendijk P, Mur G, Van der Velde ET, Baan J. The four electrode resistivity technique in anisotropic media: Theorical analysis and application on myocardial tissue in vivo. IEEE Transations on Biomedical Engineering. 1993; 40:1138-1148 http://dx.doi.org/10.1109/10.245632

25. Zhao X, Kinouchi Y, Iritani T, Morimoto T, Takeuchi M. Estimation of Multi-Layer Tissue Conductivities from NonInvasive Measured Bioresistances Using Divided Electrodes. IEICE Trans. Inf. \& Syst. 2002;E85-D:1031-1038

26. Gómez-Sánchez JA, Aristizábal Botero W, Barragán Arango PJ, Felice CJ. Introduction of a muscular bidirectional electrical anisotropy index to quantify the structural modifications during aging in raw meat. Measurement Science and Technology. 2009;20

27. Chawla N, Chawla KK. Metal matrix composites. Springer Science + Business Media Inc, New York, 2006.

28. Grimnes S, Martinsen OG. Bioimpedance and Bioelectricity Basics. Second Edition, Elsevier, Oxford, 2008

29. Geddes LA, Foster KS, Reilly J, Voorhees WD, Bourland JD, Ragheb T, Fearnot NE. The rectification properties of an electrode-electrolyte interface operated at high sinusoidal current density. IEEE Transactions on Biomedical Engineering. 1987;34:669-672 http://dx.doi.org/10.1109/TBME.1987.325991

30. Ruiz GA, Felice CJ, Valentinuzzi ME. Non-linear response of electrode-electrolyte interface at high current density. Chaos, Solutions and Fractals. 2005;25:649-654 http://dx.doi.org/10.1016/j.chaos.2004.11.029

31. Høyum P, Kalvøy H, Martinsen OG, Grimnes S. A finite element model of needle electrode spatial sensitivity. Physiol. Meas. 2010;31:1369-1379 http://dx.doi.org/10.1088/0967-3334/31/10/006

32. Pajkossy T. Impedance spectroscopy at interfaces of metals and aqueous solutions - Surface roughness, CPE and related issues. Solid State Ionics. 2005;176:1997-2003 http://dx.doi.org/10.1016/j.ssi.2004.06.023

33. Feldman Y, Nigmatullin R, Polygalov E, Texter J. Fractalpolarization correction in time domain dielectric spectroscopy. Physical Review E. 1998;58:7561-7565 http://dx.doi.org/10.1103/PhysRevE.58.7561

34. Halley JW, Studies of the interdependence of electronic and atomic dynamics and structure at the electrode-electrolyte interface. Electrochimica Acta. 1996;41:2229-2251 http://dx.doi.org/10.1016/0013-4686(96)00052-7

35. Kalvøy H, Johnsen GK, Martinsen OG, Grimnes S. New Method for Separation of Electrode Polarization Impedance from Measured Tissue Impedance. The Open Biomedical Engineering Journal. 2011;5:8-13 http://dx.doi.org/10.2174/1874120701105010008

36. Kottam ATG. Measurement of Electrical Admittance to Study the Onset and Progression of Myocardial Ischemia. ProQuest, USA, 2007 